\title{
Direct targets of the transcription factors ABA-Insensitive(ABI)4 and ABI5 reveal synergistic action by ABI4 and several bZIP ABA response factors
}

\author{
Wendy M. Reeves • Tim J. Lynch • Raisa Mobin • \\ Ruth R. Finkelstein
}

Received: 24 August 2010/ Accepted: 3 January 2011/Published online: 19 January 2011

(C) The Author(s) 2011. This article is published with open access at Springerlink.com

\begin{abstract}
The plant hormone abscisic acid (ABA) is a key regulator of seed development. In addition to promoting seed maturation, $\mathrm{ABA}$ inhibits seed germination and seedling growth. Many components involved in ABA response have been identified, including the transcription factors ABA insensitive (ABI)4 and ABI5. The genes encoding these factors are expressed predominantly in developing and mature seeds, and are positive regulators of ABA mediated inhibition of seed germination and growth. The direct effects of ABI4 and ABI5 in ABA response remain largely undefined. To address this question, plants over-expressing ABI4 or ABI5 were used to allow identification of direct transcriptional targets. Ectopically expressed ABI4 and ABI5 conferred ABA-dependent induction of slightly over 100 genes in 11 day old plants. In addition to effector genes involved in seed maturation and reserve storage, several signaling proteins and transcription factors were identified as targets of ABI4 and/or ABI5. Although only $12 \%$ of the ABA- and ABI-dependent transcriptional targets were induced by both $\mathrm{ABI}$ factors in 11 day old plants, $40 \%$ of those normally expressed in seeds had reduced transcript levels in both abi4 and abi5 mutants. Surprisingly, many of the ABI4 transcriptional targets do not contain the previously characterized ABI4 binding motifs, the CE1 or S box, in their promoters, but some of these interact with ABI4 in electrophoretic
\end{abstract}

Electronic supplementary material The online version of this article (doi:10.1007/s11103-011-9733-9) contains supplementary material, which is available to authorized users.

W. M. Reeves · T. J. Lynch · R. Mobin · R. R. Finkelstein ( $\square)$ Molecular, Cellular, and Developmental Biology Department, University of California at Santa Barbara, Santa Barbara, CA 93106, USA

e-mail: finkelst@lifesci.ucsb.edu mobility shift assays, suggesting that sequence recognition by ABI4 may be more flexible than known canonical sequences. Yeast one-hybrid assays demonstrated synergistic action of ABI4 with ABI5 or related bZIP factors in regulating these promoters, and mutant analyses showed that ABI4 and these bZIPs share some functions in plants.

Keywords ABA · Arabidopsis · ABI4 - ABI5 · Transcriptional targets

\section{Introduction}

Abscisic acid (ABA) regulates many agronomically important aspects of plant seed development, including synthesis of seed storage proteins and lipids, seed desiccation tolerance, dormancy, germination and the subsequent commitment to seedling growth (Finkelstein et al. 2002). Genetic studies, especially in Arabidopsis, have identified a large number of loci involved in $\mathrm{ABA}$ response. Digenic analyses indicate that these loci are likely to be acting in multiple overlapping response pathways. In addition to interactions among regulators of $\mathrm{ABA}$ response, there appears to be substantial cross-talk between signaling pathways regulating response to $\mathrm{ABA}$ and to other plant hormones, assorted stresses, and sugars (Acharya and Assmann 2009; Finkelstein and Gibson 2002; Shinozaki and Yamaguchi-Shinozaki 2007).

Three well-characterized positive regulators of $\mathrm{ABA}$ signaling are the transcription factors encoded by $A B I 3$, $A B I 4$ and $A B I 5$, which were initially identified in screens for mutants exhibiting ABA-resistant germination. These proteins are members of the B3-, APETALA2- (AP2), and basic leucine zipper- (bZIP) domain families, respectively, and regulate overlapping subsets of seed-specific and/or 
ABA-inducible genes (Finkelstein and Lynch 2000; Finkelstein et al. 1998; Giraudat et al. 1992; Lopez-Molina and Chua 2000). ABI5 has many close homologs, including ABA-Response Element Binding Factors (ABFs and AREBs) and Arabidopsis thaliana Dc3 Promoter Binding Factors (AtDPBFs), that also participate in ABA or stress signaling, primarily at later stages of growth (Choi et al. 2000; Kim et al. 2002; Uno et al. 2000).

Physiological studies have shown that the $A B I 3, A B I 4$, and $A B I 5$ loci have similar qualitative effects on seed development and ABA sensitivity, consistent with action in overlapping pathways, but that null mutations in $A B I 3$ are more severe than those in $A B I 4$ or $A B I 5$ (Finkelstein and Lynch 2000; Finkelstein et al. 1998; Parcy et al. 1994). Both $\mathrm{ABI} 3$ and ABI4 are expressed from globular stage embryogenesis onward, and can regulate expression of ABI5, which is activated by heart stage. All three are most highly expressed in mature seeds, but differ slightly in localization within the seeds (Brocard et al. 2002; Finkelstein and Lynch 2000; Lopez-Molina et al. 2001; Parcy et al. 1994; Penfield et al. 2006; Söderman et al. 2000).

Although abi4 and abi5 mutants were initially thought to have ABA- and seed-specific defects (Finkelstein 1994), they have also been shown to have defects in response to glucose, $\mathrm{NaCl}$, and osmotic inhibition of germination and/or seedling growth, as well as displaying ABA-resistant seedling growth (Arenas-Huertero et al. 2000; Brocard et al. 2002; Laby et al. 2000; Quesada et al. 2000). Continued low levels of expression in vegetative growth are sufficient to modulate additional responses, as evidenced by ABIdependent effects on lateral root growth, carbon metabolism, and retrograde signaling from plastids or mitochondria to the nucleus (Giraud et al. 2009; Koussevitzky et al. 2007; Rook et al. 2001; Signora et al. 2001).

In addition to mutant analyses, gain-of-function studies show extensive cross-regulation of expression among $A B I 3, A B I 4$, and $A B I 5$ (Söderman et al. 2000) and overexpression of any of these $\mathrm{ABI}$ transcription factors results in $\mathrm{ABA}$ or glucose hypersensitivity in vegetative tissues (Finkelstein et al. 2002). Overexpression of $A B I 3$ or $A B I 4$ is even sufficient to confer ABA-inducible vegetative expression of several "seed-specific" genes, which is partly dependent on increased $A B I 5$ expression (Söderman et al. 2000). $A B I 5$ overexpression can restore wild-type ABA sensitivity during germination and seedling growth to a weak abi3 mutant (Lopez-Molina et al. 2002) and results in enhanced ABA induction of some genes normally regulated by $\mathrm{ABA}$ in vegetative tissues. These results suggest that seed-specific or ABA-inducible expression might be at least partially controlled by regulatory complexes containing combinations of these transcription factors.

$\mathrm{ABI} 5$ and its $\mathrm{ABF} / \mathrm{AREB} / \mathrm{AtDPBF}$ homologs bind to the class of G-box motifs known as ABA response elements
(ABREs). Some members of this bZIP subfamily have been shown to regulate expression of themselves and each other, and function redundantly in response to some stresses (Finkelstein et al. 2005; Yoshida et al. 2010). ABI4 is also a member of a large transcription factor family which includes the Drought Response Element Binding factors (DREBs) and Ethylene Response Element Binding Proteins (EREBPs), but it differs from ABI5 in that it is an orphan member. Although classified as part of the DREB subfamily, based on up to $75 \%$ homology within the AP2domain, there are no obvious candidates for factors with redundant function. In vitro selection of maize $\mathrm{ABI} 4$ binding sites identified a consensus of CACCK (Niu et al. 2002), which differs slightly from the DREB and EREBP consensus binding sites of RCCGAC (DRE) and TAAGAGCCGCC (GCC box), respectively (Ohme-Takagi and Shinshi 1995; Sakuma et al. 2002).

Studies of sugar- and light-regulated gene expression have shown that ABI4 mediates ABA- and sugar-repression of photosynthetically associated nuclear genes, and that this is correlated with ABI4 binding to a motif designated the S-box [CACYKSCA] (Acevedo-Hernandez et al. 2005). The S-box is similar to the maize ABI4 binding consensus [CACCK] and is present in close association with G-boxes characteristically bound by bZIP factors. A different motif, consisting solely of the bases CCAC, has been correlated with ABI4-dependent retrograde signaling, particularly when adjacent to, or overlapping with, a $G$ box motif (Koussevitzky et al. 2007). Although most of these studies focused on ABI4-repressed genes, ABI4-inducible gene expression has also been demonstrated to be dependent on sequences related to the S-box (Bossi et al. 2009).

Several studies have reported ABI-dependent gene expression based on altered transcript accumulation in mutants (Nakabayashi et al. 2005; Penfield et al. 2006), but these do not distinguish between direct and indirect regulation. To focus on direct targets of ABI4 and ABI5 regulation, we performed a preliminary microarray screen (assisted by the Laboratory for Functional Genomics at TAMU) comparing ABA-responsive gene expression in $35 S: A B I$ versus abi lines in 11 day old plants, a developmental stage when the $35 \mathrm{~S}: A B I$ expression is mainly ectopic and most of the normally redundantly functioning regulators are not active.

Our major hypothesis was that ABI4 and ABI5 might directly regulate some common targets, including signaling components generally assumed to act upstream of transcription factors, as well as novel components of $\mathrm{ABA} /$ ABI-dependent signaling. Preliminary analyses of replicate biological material for each genotype with the nearly full Arabidopsis genome Affymetrix ATH1 chips (approximately $24 \mathrm{~K}$ genes represented) identified slightly over 100 
transcriptional target genes whose expression was enhanced in the 35S:ABI4 and/or 35S:ABI5 lines. Despite the similarity in growth phenotype of the $A B I 4$ and $A B I 5$ overexpression lines, only about $12 \%$ of these target genes were regulated by both $A B I 4$ and $A B I 5$, and their common targets were mostly members of the late embryogenesis abundant (lea) class or encoded proteins of unknown function. The ABI-induced genes include both positive and negative regulators of $\mathrm{ABA}$ signaling, including a member of the clade of PP2Cs recently shown to interact directly with the PYR/PYL/RCAR class of ABA receptors. Surprisingly, although the ABI4-regulated genes were very tightly co-regulated in a manner distinct from the ABI5regulated genes, most of their promoters lacked the previously identified ABI4 binding site, but were instead highly enriched for ABREs, i.e. bZIP binding sites. However, several of these promoters still bound to ABI4 in vitro, and could be activated synergistically by ABI4 and specific bZIPs.

\section{Materials and methods}

\section{Plant materials}

Arabidopsis plants were grown under continuous light. The abi4-1 and abi5-1 mutants were isolated as described in Finkelstein (1994). The overexpression lines used for the microarrays were those with the most active transgenes described in Brocard et al. (2002), and Söderman et al. (2000): line 114A for 35S:ABI4 and line 2D1 for 35S:ABI5. The knockout lines used were SALK_043079 (ABF1) and SALK_075836 (ABF3) produced by Alonso et al. (2003). All mutants are in the Columbia background except abi5-1, which is in the Ws background; the original overexpression lines are both in the Ws background. Comparisons of bZIP mutant effects on seedling gene expression used the abi5-7 mutant in the Col background, described in Nambara et al. (2002). Following loss of the 35S:ABI4 line due to inactivation of the transgene, we constructed a 35S:GFP:ABI4 fusion by insertion of an $A B I 4$ cDNA into the EcoRI site of pEGAD (accession no. AF218816) (Cutler et al. 2000). This fusion includes all but the first two and final amino acids of ABI4. This construct was introduced into Columbia ecotype and abi4-1 plants by Agrobacterium mediated transformation using the floral dip method (Clough and Bent 1998), and transgenic lines were selected on the basis of BASTA resistance. Although GFP fluorescence was not detectable in lines carrying this construct, function of the transgene was tested in terms of its ability to complement ABA-resistance of the abi4 mutant and confer ABA and glucose hypersensitivity in the wild type background.
For plants to be used for RNA extractions, seeds were surface-sterilized with $5 \%$ hypochlorite and $0.02 \%$ Triton $\mathrm{X}-100$, then rinsed several times with sterile water before plating on GM $(0.5 \times$ Murashige-Skoog salts, $1 \%$ sucrose $)$ solidified with $0.55 \%$ agar. The seeds were stratified at $4^{\circ} \mathrm{C}$ for 3 day, then incubated at $22^{\circ} \mathrm{C}$ in continuous light (50-70 $\mu \mathrm{E} \mathrm{m}^{-2} \mathrm{~s}^{-1}$ ) for 11 day prior to $4 \mathrm{~h}$ treatments with or without $50 \mu \mathrm{M}$ ABA and/or $20 \mu \mathrm{M}$ cycloheximide (CHX). To minimize disturbance of the roots, plants were treated by flooding the plates with $4 \mathrm{ml} \mathrm{GM}$ supplemented with $\mathrm{ABA}, \mathrm{CHX}$, or equal volumes of their respective solvents (50\% DMSO for ABA, ethanol for $\mathrm{CHX}$ ) for control treatments. Following incubation, plants were harvested, frozen in liquid nitrogen, and stored at $-80^{\circ} \mathrm{C}$ until RNA was extracted.

Seed and seedling samples were sterilized as above, then plated on minimal nutrient salts solidified with $0.7 \%$ agar, with or without $5 \mu \mathrm{M}$ ABA, $166.5 \mathrm{mM} \mathrm{NaCl}, 333 \mathrm{mM}$ glucose or $333 \mathrm{mM}$ sorbitol. Seedlings harvested at 2.5 day post-stratification were incubated on GM with or without $5 \mu \mathrm{M}$ ABA. Germination and seedling growth assays testing $\mathrm{ABA}$ and stress sensitivities of various mutant lines used minimal nutrient salts solidified with $0.7 \%$ agar, with or without $\mathrm{ABA}$ concentrations ranging from 3 to $30 \mu \mathrm{M}$, $200 \mathrm{mM} \mathrm{NaCl}, 400 \mathrm{mM}$ sorbitol or $333 \mathrm{mM}$ glucose.

RNA gel blots

Total RNA was isolated by hot phenol extraction, as previously described (Söderman et al. 2000), then size fractionated on MOPS [3-( $N$-morpholino)-propanesulfonic acid]-formaldehyde gels and transferred to nylon membranes (Osmonics, Westborough, MA) using 20× SSPE $(1 \times \mathrm{SSPE}$ is $0.115 \mathrm{M} \mathrm{NaCl}, 10 \mathrm{mM}$ sodium phosphate, and $1 \mathrm{mM}$ EDTA, pH 7.4) as blotting buffer. RNA was bound to the filters by UV cross-linking $\left(120 \mathrm{~mJ} \mathrm{~cm}^{-2}\right.$ at $\left.254 \mathrm{~nm}\right)$. Uniformity of loading and transfer was assayed qualitatively by methylene blue staining and quantitatively by hybridization to an rDNA probe. Transcripts from ABAinducible genes were detected by hybridization to cDNA clones or PCR fragments as described by Söderman et al. (2000), labeled by random priming to a specific activity of $10^{8} \mathrm{cpm} \mu \mathrm{g}^{-1}$. Hybridization conditions for abundant transcripts were $50 \%$ formamide, $5 \times$ SSPE, $5 \times$ Denhardt's solution $(1 \times$ Denhardt's solution is $0.02 \%$ Ficoll, $0.02 \%$ polyvinylpyrrolidone, and $0.02 \% \mathrm{BSA}), 0.1 \% \mathrm{SDS}$, and $200 \mathrm{mg} \mathrm{ml}^{-1}$ of DNA at $43^{\circ} \mathrm{C}$ for $16-24 \mathrm{~h}$ in a Hyb-Aid rotisserie oven. Filters were washed twice at $60^{\circ} \mathrm{C}$ in $2 \times$ $\mathrm{SSC}(1 \times \mathrm{SSC}$ is $0.15 \mathrm{M} \mathrm{NaCl}$ and $0.015 \mathrm{M}$ sodium citrate) and $0.1 \% \mathrm{SDS}$ and once at $60^{\circ} \mathrm{C}$ in $0.2 \times \mathrm{SSC}$ and $0.1 \%$ SDS for 30-60 $\mathrm{min}$. Low abundance transcripts were detected by hybridization to a random-priming labeled probe in $7 \%$ SDS, 0.5 M sodium phosphate, $\mathrm{pH} 7.2,1 \mathrm{mM}$ EDTA, and 
$1 \%$ BSA at $65^{\circ} \mathrm{C}$ for $16-24 \mathrm{~h}$ (Church and Gilbert 1984). The final wash for these filters was $40 \mathrm{mM}$ Na phosphate buffer, $\mathrm{pH} 7.2,1 \%$ SDS, and $1 \mathrm{mM}$ EDTA at $60-65^{\circ} \mathrm{C}$. Bound probe was detected by phosphoimager (BioRad) then visualized and quantified with Quantity One software.

\section{Promoter analysis}

Promomer (http://bar.utoronto.ca/ntools/cgi-bin/BAR_Pro moter.cgi) (Toufighi et al. 2005) was used to search the promoters of our microarray target sets for known transcription factor motifs. Promoters were defined as 1,000 bp upstream of the transcription start site as identified in the TAIR7 annotation, and searches were performed for motifs in the $5^{\prime}$ to $3^{\prime}$ orientation on both strands. $P$-value was calculated in MatLab using the formula $P$-value $=1-$ sum(hygepdf $(0: k, N, n, m))$, where $\mathrm{k}=\mathrm{x}-1$ ( $\mathrm{x}=$ hits in target set), $\mathrm{m}=$ total genes in target set, $\mathrm{n}=$ hits in genome, and $\mathrm{N}=$ total genes in genome.

Yeast assays

Promoter-lacZ reporter fusions were constructed by amplifying promoter fragments with primers including XhoI and Sph1 linkers and cloning into pGEM-T Vector System (Promega) After sequencing, promoters were subcloned into the $\mathrm{Xhol} / \mathrm{Sph} 1$ sites of $\mathrm{pLG} \Delta 178$, a derivative of the plasmid pLG $\Delta 312$ (Guarente and Mason 1983). Reporter clones were transformed into the yeast strain

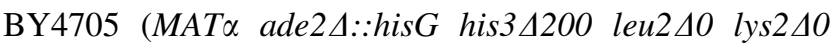
met15 40 trp1 $\Delta 63$ ura3 $\Delta 0$ ) (Brachmann et al. 1998) using the Alkali Cation transformation kit (Bio101) following the manufacturer's instructions; transformants were selected by complementation of uracil auxotrophy.

Fusions of the GAL4 activation domain and transcription factors to be tested (ABI4, $\mathrm{ABI} 5, \mathrm{ABF} 1$ and $\mathrm{ABF} 3$ ) were constructed using a CRE-lox system to recombine cDNAs in the pUNI51 vector to the pACT2lox vector (Liu et al. 1998). The ABF1 cDNA was stock \# U19471, available through the ABRC; all others were constructed by subcloning previously isolated cDNAs into pUNI51. ABF3 was subcloned from a Gateway entry clone, ABRC stock \# U15508. AD fusions were transformed into the yeast strain THY.AP4 (MATa ura3 leu2 lexA::lacZ::trp1 lexA::HIS3 lexA::ADE2) (Obrdlik et al. 2004) and transformants selected by complementation of the leu2 auxotrophy. To test potential activation by pairs of transcription factors, the pACT2lox vector was modified by in vivo recombination of an amplified TRP1 gene to replace the LEU2 gene, such that lines carrying two transcription factor fusions could be constructed by retransformation of the initial AD fusion line and selection for complementation of both leu and trp auxotrophy.
To test transactivation of the reporter fusions, yeast carrying the reporters and $\mathrm{AD}$ fusions or vector controls were mated by incubation overnight on YPD, then replica plated to YSM lacking uracil, leu and trp to select for diploids carrying all three plasmids. Activation of the lacZ reporter was pre-screened by colony lifts transferring yeast to Whatman \#1 filters, which were then subjected to 3 rounds of freeze-thaw cycles in liquid nitrogen, then overnight incubation at $37^{\circ} \mathrm{C}$ on a $3 \mathrm{MM}$ filter saturated with $Z$ buffer (113 mM Na2HPO4, $40 \mathrm{mM}$ NaH2PO4, $10 \mathrm{mM} \mathrm{KCl}, 1 \mathrm{mM} \mathrm{MgSO} 4, \mathrm{pH} 7), 200 \mu \mathrm{g} / \mathrm{ml} \mathrm{Xgal}$ and $38 \mathrm{mM} \beta$-mercaptoethanol. Quantitative $\beta$-galactosidase assays were performed as described at http://labs.fhcrc.org/ gottschling/Yeast\%20Protocols/Bgal.html.

\section{EMSAs}

Electrophoretic mobility shift assays (EMSAs) were performed with fusions of GST and the DNA binding domain of ABI4 (amino acids 1-114). The ABI4 DNA binding domain was amplified with primers containing the EcoRI site (forward: CGTACTGAATTCATGGACCCTTTAGCT TCCCAAC; reverse: CGTACTGAATTCTCAAGACGAA GGGGTTAGTTGAGCTG) and cloned into the EcoRI site of pBluescript. After sequencing, the ABI4 DNA binding domain was subcloned into the EcoRI site of pGEX, downstream of GST. The fusion protein was expressed in BL21 C + cells using Overnight Express ${ }^{\mathrm{TM}}$ Instant TB medium (Novagen). Cells were harvested, resuspended in $1 \times$ PBS $+0.2 \mathrm{mM}$ PMSF $+1 \mathrm{mg} / \mathrm{ml}$ lysozyme (Sigma), then frozen at $-70^{\circ} \mathrm{C}$ for $30 \mathrm{~min}$ and thawed before sonicating repeatedly on ice. After sonication, Triton X-100 was added to $1 \%$ and the sonicate was incubated for $30 \mathrm{~min}$ at $4^{\circ} \mathrm{C}$ for $30 \mathrm{~min}$. The soluble fraction was then incubated with Glutathione agarose (Sigma) for $30 \mathrm{~min}$ at $4{ }^{\circ} \mathrm{C}$ and loaded onto an Econo-column (BioRad). Beads were washed $3 \times$ with PBS before GST-ABI4 was eluted three times with $10 \mathrm{mM}$ glutathione in $25 \mathrm{mM}$ Tris, $\mathrm{pH}$ 8.0. Eluted purified protein was stored at $-80^{\circ} \mathrm{C}$; small aliquots were diluted to make a working stock of $100 \mathrm{ng} / \mu \mathrm{l}$ in $20 \mathrm{mM}$ Tris $\mathrm{pH} 8,10 \%$ glycerol and $1 \mathrm{mM}$ EDTA.

Fragments used as probes for EMSAs were upstream regions of genes that were highly induced by $\mathrm{ABA}$ in 11 day old 35S-ABI4 plants. Three of these had small intergenic regions such that probes were at most $316 \mathrm{bp}$ long:

Atlg32560 (nt -305 to +6 relative to trancription start site)

At4g16160 (nt -264 to +17 relative to trancription start site)

At1g27470 (nt -301 to +15 relative to translation start site) 
For those with larger intergenic regions, 200-300 bp fragments containing most of the ABREs and/or CCAC motifs in each upstream region were amplified or digested from the yeast one-hybrid subclones. These included:

$$
\begin{aligned}
& \text { At } 2 \mathrm{~g} 25890 \text { (nt }-445 \text { to }-144 \text { relative to transcription } \\
& \text { start site) } \\
& \text { At3g17520 (nt }-336 \text { to }-130 \text { relative to transcription } \\
& \text { start site) } \\
& \text { At } 4 \mathrm{~g} 25140 \text { ( } \mathrm{nt}-178 \text { to }-36 \text { relative to transcription } \\
& \text { start site or }+23 \text { relative to translation start site) }
\end{aligned}
$$

In addition, the 5' upstream fragment of ABI4 described in Bossi et al. (2009) was used as a positive control.

These fragments were amplified and cloned as described for construction of the yeast one-hybrid reporter fusions. Fragments were re-amplified from subclones using vectorspecific primers, then released from vector sequences by restriction digestion with XhoI and/or SalI. In addition, smaller fragments of these probes were produced by restriction digestion or PCR as indicated in the figure legends. Fragments were end-labeled by fill-in reactions in a volume of $20 \mu \mathrm{l}$ including $30 \mathrm{ng}$ fragment, $1 \times$ DNA polymerase buffer (Promega), 4-10 $\mu \mathrm{Ci} 32 \mathrm{P}-\mathrm{dCTP}, 3$ units Klenow fragment of DNA polymerase and supplemented with $50 \mu \mathrm{M}$ dTTP as needed, depending on the overhang sequence. After $10 \mathrm{~min}$ incubation at room temperature, reactions were diluted to $50 \mu \mathrm{l}$ with TE and unincorporated dNTPs were removed by spin-column chromatography.

Binding reactions were performed in $15 \mu \mathrm{l}$ volumes containing approximately $1 \mathrm{ng}$ probe $(2,000-4,000 \mathrm{cpm})$, $100 \mathrm{ng}$ polydIdC, $1 \mu \mathrm{g}$ BSA, with or without $100 \mathrm{ng}$ GST or GST-ABI4 in $1 \times$ binding buffer $(20 \mathrm{mM}$ Tris $\mathrm{pH} 8$, $7.5 \mathrm{mM} \mathrm{MgCl} 2,10 \mathrm{mM} \mathrm{KCl}, 0.5 \mathrm{mM}$ DTT, $0.2 \mathrm{mM}$ EDTA, $10 \%$ glycerol). For competition assays, unlabeled probe fragments were included at $50-100 \times$ excess relative to the labeled probe. The non-specific competitors were either the 3'UTR of ABI4 described in Bossi et al. (2009) or bulk herring testes DNA. Reactions were incubated for $30 \mathrm{~min}$ at room temperature, then loaded immediately on a $4.5 \%$ acrylamide $1 \times$ TBE gel that had been pre-run at $120 \mathrm{~V}$. Loading dye was added to the free probe sample and gels were run at $190 \mathrm{~V}$ until the BPB was approximately $1 \mathrm{~cm}$ from the bottom. Gels were lightly fixed with a mixture of $10 \%$ acetic acid and $10 \%$ methanol, then dried and exposed to a phosphorimager screen.

\section{Results}

Direct targets of $\mathrm{ABI} 4$ and $\mathrm{ABI} 5$ regulation

To emphasize the effects of ABI4 and ABI5 expression, we analyzed 11 day old seedlings, a developmental stage when seed specific transcription factors are not normally expressed but overexpression of ABI4 or ABI5 enhances ABAinducible responses (Brocard et al. 2002; Söderman et al. 2000). Each ABI factor was constitutively overexpressed under control of the CaMV 35S promoter and ABA response was transiently induced by treating with $50 \mu \mathrm{MABA}$ for $4 \mathrm{~h}$. Cycloheximide was added at the same time to limit expression of indirect targets. ABA-dependent gene expression was identified by comparing transcriptomes of $35 S: A B I$ seedlings treated with $\mathrm{ABA}$ and cycloheximide to seedlings treated with cycloheximide alone. ABI-dependent genes were then identified by comparison of $35 S: A B I$ versus abi mutant seedlings treated with both ABA and cycloheximide (Supp. methods). Direct ABI4 and ABI5 targets were defined as genes that were ABA induced at least twofold in the overexpression plants compared to the abi mutant plants. The absolute number of targets identified by this strategy depends on the strength of transgene expression, the developmental stage of the tissue, and the fold difference chosen as the criterion for ABA/ABI-regulation, and is therefore likely to be an underestimate, yet still informative regarding functional classes and structural characteristics of these transcriptional targets. In this study, the ABI4 and ABI5 overexpression lines each reproducibly induced less than 100 ABA- and ABI-dependent genes (95 and 59, respectively). There was relatively little overlap between the two sets of targets, with just 16 shared genes (Supp. Table 1).

The genes induced by ABI4 and by ABI5 represent many functional classes (Table 1). As expected, given the roles of $\mathrm{ABI} 4$ and $\mathrm{ABI} 5$ in seed development, a high percentage of the target genes were seed maturation related genes, including leas, oleosins and dehydrins. The majority of these seed maturation genes were induced only by ABI4 (18 genes) or by both ABI4 and ABI5 (10 genes). Only two seed maturation related genes were induced solely by ABI5, consistent with previous analyses of ABI5 overexpression (Brocard et al. 2002).

ABI4 and ABI5 also induced a variety of other gene targets. Both induced multiple transcription factors and signaling molecules, possibly involved in propagating the ABA signal. Interestingly, we also identified negative regulators of ABA signaling, including the protein phosphatase type 2C ABA hypersensitive at germination (AHG)1 (Nishimura et al. 2007). In addition, two ABI5 interacting factors previously characterized as negative regulators of ABA and stress signaling were identified as transcriptionally induced by ABI4: AFP2 and AFP3 (Garcia et al. 2008). These results show that negative feedback regulation is being induced alongside positive effector proteins.

Validation of exogenous overexpression targets

To confirm that we had identified genes specifically induced by $\mathrm{ABI} 4$ or $\mathrm{ABI} 5$ overexpression and $\mathrm{ABA}$ 
Table 1 Functions of ABI/ABA induced genes. Function was determined based upon published reports, functions of homologs, and presence of known protein domains within gene. Genes were then sorted into related functional classes. The seed maturation category includes leas, oleosins, dehydrins and other genes expressed/required during seed maturation. Protein stability includes proteases and protease inhibitors not associated with seed maturation. Cell structure includes expansins and other genes involved in cell wall synthesis. The signaling category contained kinases and phospholipases. Stress/ disease response genes included heat shock proteins, avirulence response genes and stress inducible genes. Metabolism included most other genes of known function not associated with another category

\begin{tabular}{|c|c|c|c|c|c|}
\hline Gene function & ABI4 & ABI4 specific & Shared & ABI5 specific & ABI5 \\
\hline Seed maturation & 28 & 18 & 10 & 2 & 12 \\
\hline Hormone response & 4 & 4 & 0 & 1 & 1 \\
\hline Metabolism & 13 & 13 & 0 & 9 & 9 \\
\hline Protein stability & 2 & 2 & 0 & 3 & 3 \\
\hline Cell structure & 2 & 2 & 0 & 5 & 5 \\
\hline Signaling & 2 & 2 & 0 & 3 & 3 \\
\hline Stress/disease response & 9 & 8 & 1 & 4 & 5 \\
\hline Transcription/DNA binding & 9 & 7 & 2 & 2 & 4 \\
\hline Unknown & 26 & 23 & 3 & 14 & 17 \\
\hline Total & 95 & 79 & 16 & 43 & 59 \\
\hline
\end{tabular}

treatment, we examined the expression of some transcriptional target genes in 11 day old wild-type, mutant and overexpression seedlings treated with or without ABA and/ or cycloheximide. These comparisons enabled us to distinguish those genes that were both ABA- and ABIdependent from those that failed to meet one of these criteria, and to identify genes whose expression was not reduced by cycloheximide and were therefore most likely to be primary targets. We tested 39 genes, representing $29 \%$ of the genes induced only by ABI $4,19 \%$ of those induced specifically by ABI5, and $50 \%$ of those induced by both (Supp. Table 2).

Induction of ABI4 targets was found to be very sensitive to the relative strength of ABI4 overexpression. After the microarray and initial validation analyses, ABI4 overexpression in the line used for these studies was silenced in subsequent generations. Consequently, we created new overexpression lines, with a GFP-ABI4 fusion under the control of the $35 \mathrm{~S}$ promoter, for use in continuing analysis of the identified targets. Although ABI4 function in this line was weaker than in the original 35S:ABI4 line (Supp. Fig. 1), possibly due to either reduced expression of the fusion gene or altered conformation of the fusion protein, some ABI4 transcriptional targets were still induced (Fig. 1). However, the induction of several targets was significantly weaker in the 35S:GFP:ABI4 line compared to the original 35S:ABI4 plants (Supp. Fig. 2A).

Of the 33 genes whose transcripts were detectable by RNA gel blots, 26 (79\%) reproduced the pattern observed in the initial microarrays. However, only 16 (48\%) met the more stringent criteria of depending solely on simultaneous $\mathrm{ABA}$ treatment and $\mathrm{ABI}$ over-expression for induction, and maintaining ABI-dependent induction levels in the presence of cycloheximide (Fig. 1, Supp. Fig. 2, Supp. Table 2).

Endogenous expression of ABI4 and ABI5 targets

The goal of this study was to identify genes that were $\mathrm{ABA} / \mathrm{ABI}$ transcriptional targets during normal plant development. ABI4 and ABI5 are most strongly expressed in seeds and young seedlings exposed to ABA or stresses such as $\mathrm{NaCl}$ or high glucose levels, so we compared expression in wild-type versus $a b i$ mutants at these stages. Analysis of publicly available microarrays using the BioArray Resource for Plant Functional Genomics (BAR) (Toufighi et al. 2005) confirmed that the majority (64\%) of our target genes are expressed in either dry or $24 \mathrm{~h}$ imbibed seeds, with expression higher in dry seeds than in waterimbibed seeds for over $90 \%$ of seed-expressed genes (Supp. Table 3).

Furthermore, many of these genes have reduced expression in abi4 and abi5 mutants (Nakabayashi et al. 2005). Nearly $90 \%$ of the seed-expressed ABI4 targets identified in our microarrays were reduced at least twofold in abi4 mutant seeds after 1 day imbibition, but less than a tenth were underexpressed in abi4 dry seeds. Nearly half of the "ABI4-specific" targets were also underexpressed in abi5 mutant seeds, predominantly at the dry seed stage. Although only $35 \%$ of our seed-expressed ABI5 targets were downregulated in abi5 mutant seeds, nearly $40 \%$ of the "ABI5-specific" targets were downregulated in abi4 mutant seeds. In contrast to the relatively few (12\%) shared targets seen in our ectopic expression screen, $40 \%$ of the seed-expressed genes were downregulated in both abi4 and abi5 mutant seeds. Based upon these expression patterns, 
Fig. 1 Confirmation of ABA and $\mathrm{ABI}$ dependent gene targets. Wild-type (Col or Ws), transgenic (35S-GFP-ABI4 or 35S-ABI5) and mutant (abi4 and abi5-1) seedlings were grown for 11 days on GM, then treated for $3 \mathrm{~h}$ with either $\mathrm{ABA}$, cycloheximide (CHX) or $\mathrm{ABA}+$ cycloheximide $(\mathrm{A} / \mathrm{X})$. Induction of $\mathrm{ABI}$ targets was assayed by Northern blot. a ABI4-regulated genes, b ABI5-regulated genes, and c genes regulated by both $\mathrm{ABI} 4$ and ABI5. For the ABI4-GFP transcript, the probe was specific to ABI4. An arrowhead indicates full length transcript and an asterisk indicates a truncated/partially degraded transcript
(A)

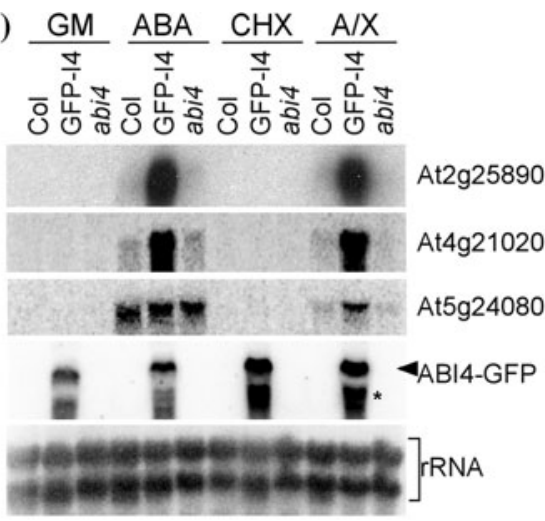

(B) $\frac{\mathrm{GM}}{\mathrm{ABA}} \frac{\mathrm{CHX}}{\mathrm{A} / \mathrm{X}}$

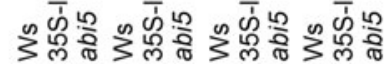

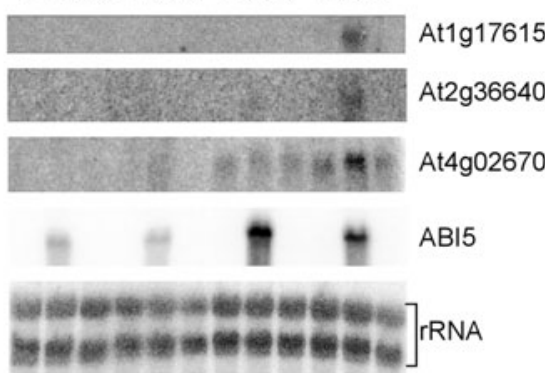

(C)

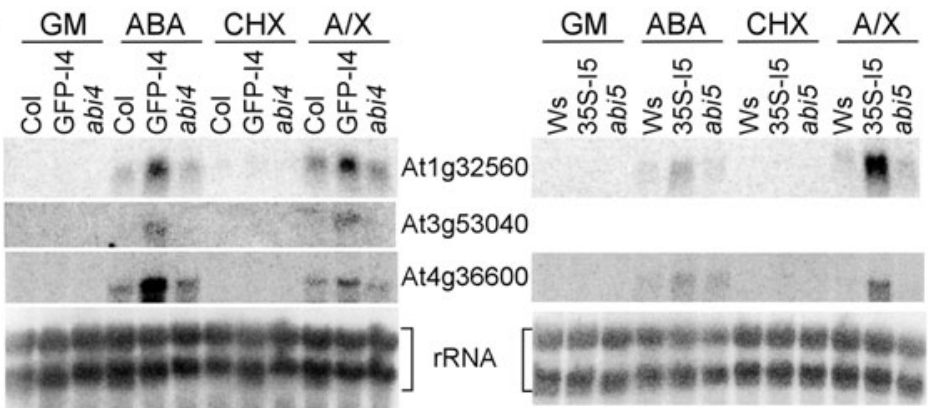

ABI4 preferentially affects continued expression during imbibition whereas ABI5 plays a slightly greater role in controlling expression of transcripts present in dry seeds.

The relative roles of these factors changes by 1 day after stratification, before any visible signs of germination have occurred. Comparisons of ABA- or stress-induced expression in wild-type versus abi mutant seeds at 1 day post stratification showed ABI5-dependent regulation by ABA and/or $\mathrm{NaCl}$ for $90 \%$ of the 20 seed-expressed genes tested (Fig. 2a, Supp. Table 4). In contrast, only $40 \%$ of these genes showed even slight defects in ABA or glucose induction between wild-type and abi4 seeds (Fig. 2b, Supp. Fig. 3, Supp. Table 4). When incubated on GM, most seeds of all genotypes tested germinate by 2.5 days post-stratification, and similar fractions (10-15\%) of wild-type and $a b i$ seeds begin germinating even in the presence of $5 \mathrm{uM}$ ABA. Despite the similarity in growth of wild-type and mutants under these conditions, all transcripts tested decreased in at least one of the abi mutant lines (Fig. 3, Supp. Table 4).

The remaining seed expressed targets identified by our ectopic expression strategy, but not downregulated in abi4 or abi5 seeds, might be redundantly regulated by the ABI factor(s) and/or additional regulators such that single mutants show no significant change in transcript levels. Furthermore, at least some of the genes identified as ABI regulated in the imbibing $a b i$ versus wild-type seed studies are likely to be indirectly regulated. For example, one-sixth of the genes tested that had been identified as ABI- regulated in dry or imbibing seeds, and in 11 day old seedlings, showed greatly reduced ABA-induction in the presence of cycloheximide (Supp. Fig. 2b, Supp. Table 2). This pattern is consistent with a requirement for synthesis of an additional signaling factor for full expression.

ABI4 and ABI5 target sets are differentially co-regulated

Using Genevestigator (Hruz et al. 2008) and BAR (Toufighi et al. 2005), we analyzed expression of target sets during development as well as in response to varied stresses and hormone treatments. As noted previously, most of the ABI4 and ABI5 target sets were expressed in mature seeds, although the ABI4 set was more enriched; $72 \%$ of ABI 4 targets, but only $53 \%$ of ABI5 targets were expressed in seeds (Supp. Table 3). In addition, roughly two-thirds of ABI4 induced genes, including over $80 \%$ of targets shared with $\mathrm{ABI}$, were co-regulated under certain stresses in older plants (Table 2, Supp. Fig. 4). They were induced in 1-7 day old seedlings by ABA treatments ranging from 0.5 to $20 \mu \mathrm{M}$ for a few hours to 2 days and by paclobutrazol (an inhibitor of GA biosynthesis), as well as by osmotic stress and salt stress in 16 day old plants. In contrast, less than a third of ABI5 specific targets were co-expressed with the ABI4 set under these conditions, suggesting that the ABI5 specific targets require higher $\mathrm{ABA}$ levels or different co-regulators for induction. Based upon these expression patterns, we 


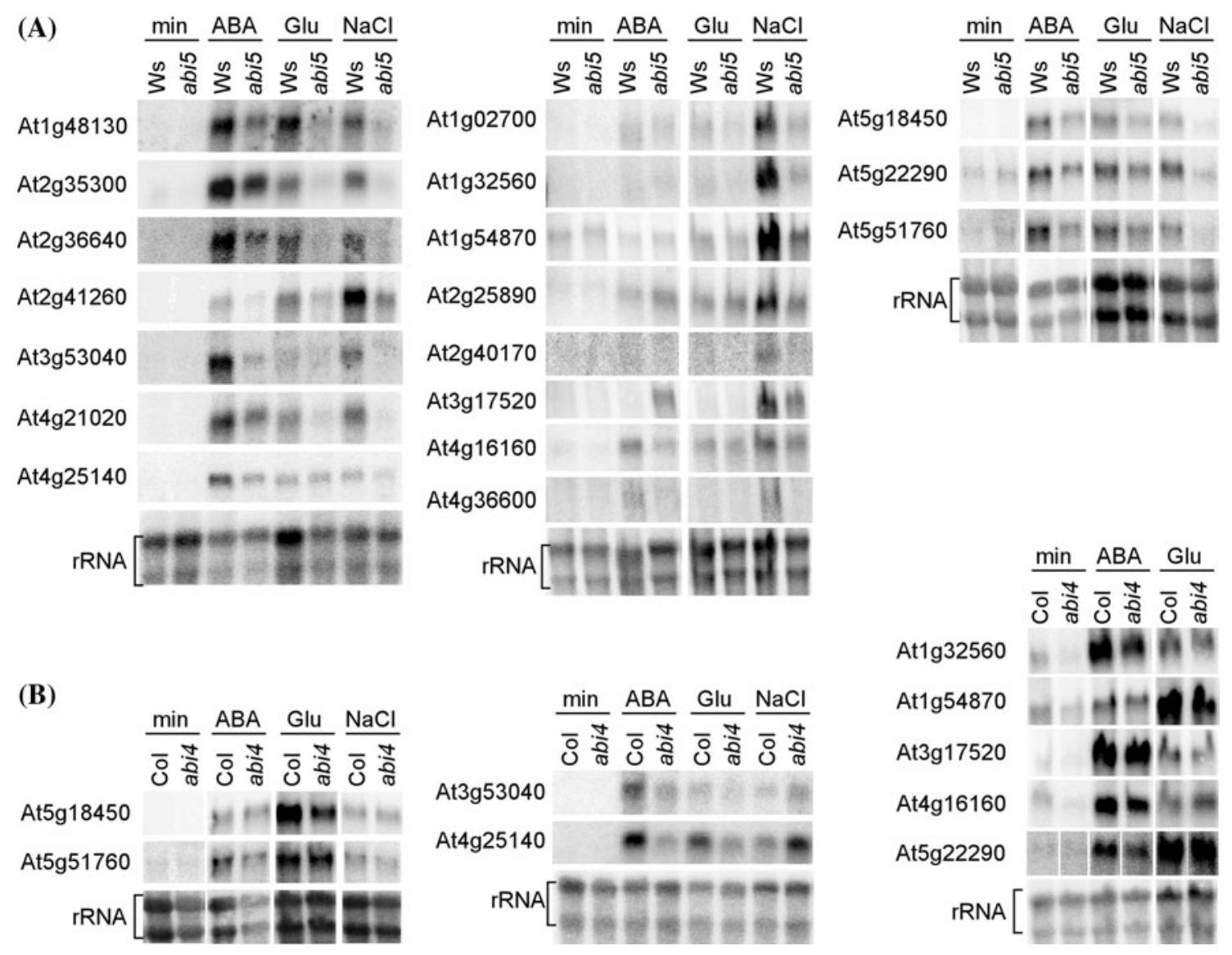

Fig. $2 \mathrm{ABA}$ and stress regulated gene expression post-stratification. Wild-type (Col or Ws) and mutant (abi4 and abi5-1) seeds were stratified for 3 days on minimal media $(\mathrm{min})$ with or without either $5 \mu \mathrm{M}$ ABA, $330 \mathrm{mM}$ Glucose or $165 \mathrm{mM} \mathrm{NaCl}$, then germinated for

expected to find significant differences in the promoters of these gene sets.

$\mathrm{ABI} 4$ and ABI5 target promoters share the same binding motifs

We used Promomer (http://bar.utoronto.ca/ntools/cgi-bin/ BAR_Promoter.cgi) (Toufighi et al. 2005) to search the promoter regions of our ABI4 and ABI5 targets for enrichment of known activator binding site motifs (Table 3). The most highly enriched motifs for both sets were variations of the ABA response element (ABRE), which has previously been shown to be bound by ABI5 and related bZIP transcription factors (reviewed in Cutler et al. 2010). The stringent ABRE (YACGTGGC) was found in 33 and $37 \%$ of our ABI4 and ABI5 target genes, respectively. This is a significant enrichment over the 5\% occurrence rate seen in a genome-wide promoter search. A slightly more degenerate version of the ABRE-like motif (BACGTGKM) is present in the majority of our target genes (75\% of ABI4 targets and $71 \%$ of ABI5 targets), but
$24 \mathrm{~h}$. RNA was extracted and transcripts were analyzed by Northern blot. a Comparison of Ws and abi5 seeds. b Comparison of $\mathrm{Col}$ and abi4

in only $21 \%$ of all promoters in the genome. The enrichment was similar even when the shared target genes were not included (data not shown). The DRE core motif, associated with the DREB class of AP2 transcription factors (Sakuma et al. 2002), was also enriched in the ABI4 target promoters, but was even more enriched in those genes regulated by ABI5.

In contrast to the ABRE and DRE motifs, previously reported ABI4 binding sites were not significantly enriched in the set of direct ABI4 targets identified in our screen (Table 3 ). The $\mathrm{S}$ box motif was very slightly, but not significantly, enriched in this ABI4 target set compared to the genome or to ABI5 target genes. However, the S-box was still present in only $16 \%$ of the ABI4 target genes, suggesting that another motif may be responsible for ABI4 binding in the co-regulated ABI4 targets. The less stringent maize ABI4 consensus site was present in $80 \%$ of the ABI4-regulated promoters, but this was not a significant enrichment over its occurrence in the genome or in ABI5regulated promoters. The CCAC motif is nearly ubiquitous, and it shows no significant enrichment in ABI4-regulated 


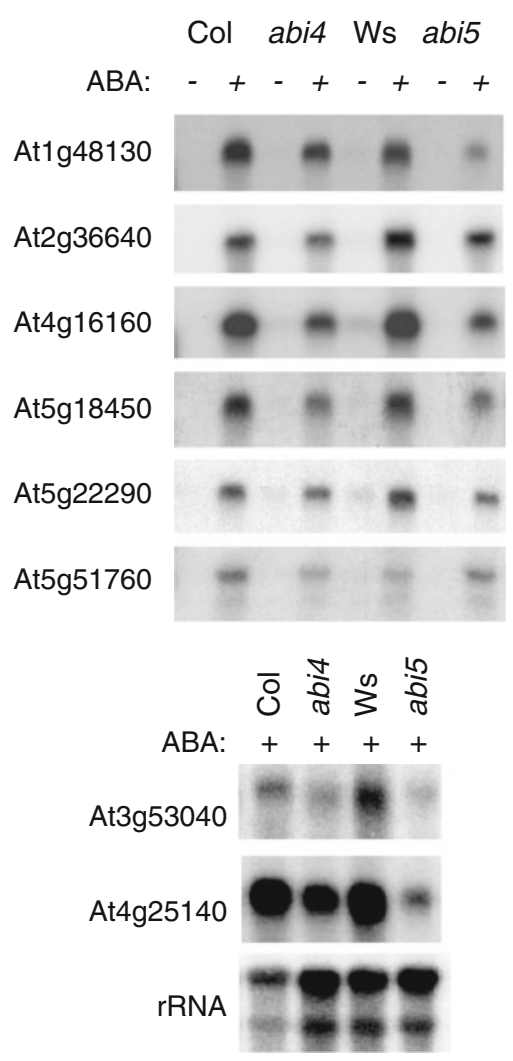

Fig. 3 ABA-regulated expression during germination. Wild-type (Col or Ws) and mutant (abi4 and abi5-1) seeds were stratified for 3 days on GM with or without $5 \mu \mathrm{M}$ ABA, then incubated for 2.5 days prior to harvest. RNA was extracted and the indicated transcripts were analyzed by Northern blot. Top panel includes GM controls. Lower panel shows only ABA-treated samples, including rRNA loading control

genes. These results suggest that the currently described ABI4 consensus binding site(s) may be an underestimate of the variability possible in ABI4 recognition sites. To

Table 2 Co-regulation of ABI4 targets by ABA and some stresses. Genevestigator (Hruz et al. 2008) was used to analyze target gene expression in response to $\mathrm{ABA}$ and stress treatment in previously determine whether any novel motifs were highly enriched in the ABI4 target set, we analyzed these promoters with AlignACE, BioProspector, MotifSampler and Weeder (Hughes et al. 2000; Liu et al. 2001; Pavesi et al. 2004; Thijs et al. 2002), but all methods identified ABRE variants as the top-scoring motifs (data not shown).

ABI4 and bZIPs synergistically activate promoters lacking previously characterized ABI4 binding sites

To determine whether ABI4-regulated promoters lacking known ABI4 binding sites but containing ABREs could interact with $\mathrm{ABI} 4$ or any bZIPs, we tested trans-activation of reporter genes in yeast. Promoters from those genes that were most strongly regulated by $\mathrm{ABI} 4$ and that lacked the S-box were cloned upstream of a $\beta$-galactosidase reporter and transformed into yeast. Plasmids encoding the GAL4 activation domain fused to full length ABI4, ABI5 or related bZIPs were transformed into yeast lines that were then mated to the reporter lines to create diploids with both reporter constructs and activator genes. The activator protein fusions rely on the DNA binding domain of the ABI or $\mathrm{ABF}$ protein for interaction with target promoters, but all are strong transcriptional activators due to the GAL4 activation domain,

As expected since these genes were largely unique to the ABI4 target set, ABI5 alone was unable to activate them in yeast. ABI4 alone also failed to activate expression from these promoters. However, some of the promoters were highly activated by either ABF1 or ABF3. Interestingly, we observed very strong synergy when both ABI4 and a bZIP (ABI5, ABF1 or ABF3) were co-expressed in yeast, with some promoters being activated up to 60 -fold in the presence of both activators (Fig. 4). These results show that

published microarrays (Goda et al. 2008; Kilian et al. 2007; Nishimura et al. 2007; Penfield et al. 2006)

\begin{tabular}{|c|c|c|c|c|c|}
\hline Seedling & Treatment & $\begin{array}{l}\text { Percent shared } \\
\text { targets }\end{array}$ & $\begin{array}{l}\text { Percent of } \\
\text { ABI4 specific }\end{array}$ & $\begin{array}{l}\text { Percent of } \\
\text { ABI5 specific }\end{array}$ & Reference \\
\hline 7 day & $10 \mathrm{uM}$ ABA, $3 \mathrm{~h}$ & 69 & 59 & 23 & Goda et al. (2008) \\
\hline 1 day & 20 uM ABA & 81 & 71 & 23 & Penfield et al. (2006) \\
\hline 2 day-wildtype & $0.5 \mathrm{uM} \mathrm{ABA}$ & 88 & 70 & 23 & Nishimura et al. (2007) \\
\hline 2 day-ahgl & $0.5 \mathrm{uM} \mathrm{ABA}$ & 94 & 73 & 33 & ibid \\
\hline 2 day-ahg3 & $0.5 \mathrm{uM} \mathrm{ABA}$ & 94 & 67 & 28 & ibid \\
\hline 1 day & 20 uM PAC & 81 & 65 & 21 & Penfield et al. (2006) \\
\hline 16 day shoots & 6-24 h $300 \mathrm{mM}$ mannitol & 88 & 66 & 40 & Kilian et al. (2007) \\
\hline 16 day roots & 6-24 h $300 \mathrm{mM}$ mannitol & 69 & 65 & 33 & ibid \\
\hline 16 day shoots & 6-24 h $150 \mathrm{mM} \mathrm{NaCl}$ & 56 & 47 & 30 & ibid \\
\hline 16 day roots & 6-24 h $150 \mathrm{mM} \mathrm{NaCl}$ & 75 & 56 & 23 & ibid \\
\hline
\end{tabular}

Genes were identified as regulated by a treatment if their expression was increased at least twofold as compared to the experimental control treatment. For each target gene set, the percent of genes that were induced by each stress treatment are shown 


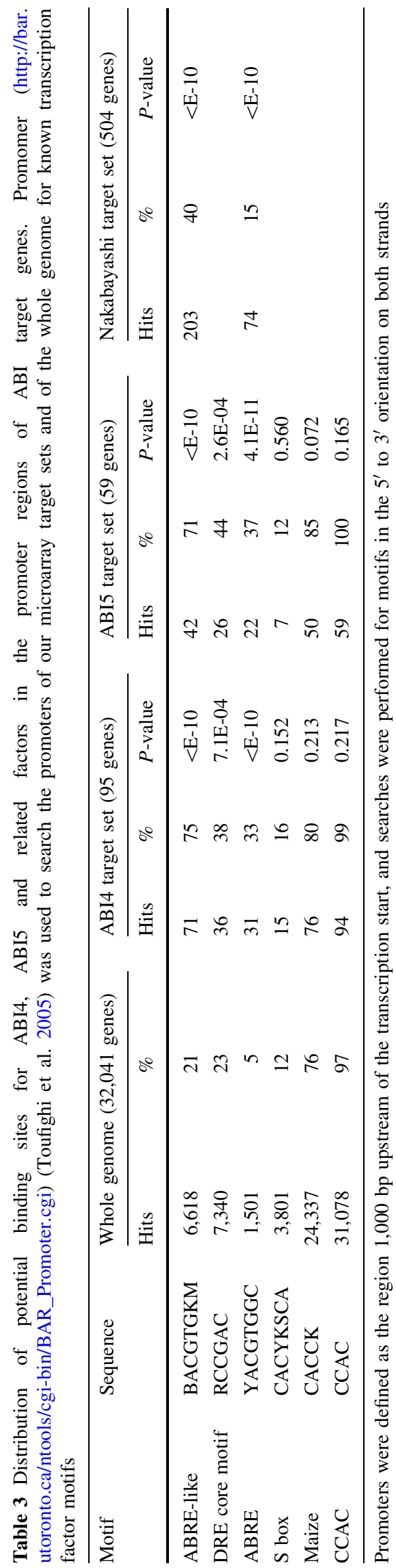

ABI4 is able to activate gene promoters that lack the previously described ABI4 binding sites, but is not sufficient to do so alone in this heterologous system.

These results suggested that both $\mathrm{ABF} 1$ and $\mathrm{ABF} 3$ might also act redundantly with ABI4 and ABI5 in early seedling development. To test the roles of these bZIPs in regulating the ABI4 transcriptional target genes in planta, we compared these ABI4 target transcript levels in wild-type, $a b i$ and $a b f$ mutant seedlings. Because our previous studies had shown that $A B F 1$ and $A B F 3$ are not highly expressed in dry seeds, but take on a larger role in ABA response in young seedlings, we assayed response at 3 and 5 day post imbibition on media supplemented with $5 \mu \mathrm{M}$ ABA. Under these conditions, the abi mutants were starting to germinate by 3 days, but germination of wild-type and the abf mutants were comparably inhibited (Supp. Fig. 5). Comparison of expression at 3 days showed that some of the ABI4regulated transcripts were also decreased in $a b f 3$ mutants (Fig. 5a). However, the magnitude of decrease was much less than the activation in yeast. For example, At3g53040 transcripts were reduced only about twofold in abf3 seedlings, but induced nearly 60 -fold by $\mathrm{ABF} 3$ alone in yeast.

To determine whether these relatively subtle effects on gene expression reflected redundant function of ABI4 and the ABFs, we analyzed double mutants. Comparison of digenic mutants with their respective parental lines showed alterations in different stress responses. The abi4 abi5 mutants had significantly enhanced ABA resistance, and slightly increased glucose resistance (Fig. 5b, c). Although combination of $a b f 3$ with abi5 also enhanced ABA and glucose resistance, abi4 abf3 mutants displayed ABA and glucose sensitivities similar to the abi4 mutant (Fig. 5b, c; Finkelstein et al. 2005). Despite the negligible effect on $\mathrm{ABA}$ and glucose sensitivity, transcript levels were further reduced in the abi4 abf 3 double mutants for some of the genes whose promoters showed synergistic activation by ABI4 and bZIP factors in yeast, e.g. At3g53040 and At4g21020 (Fig. 5a). In the case of At3g17520, which appears regulated by ABI4 and all three bZIPs tested in yeast, transcript levels were significantly reduced only in the double mutant. In contrast to these reductions in expression, $A B F 3$ was over-expressed in abi4 seedlings (Fig. 5d), similar to the previously described antagonistic regulation of $A B I 5$ and $A B F 3$ (Finkelstein et al. 2005).

ABI4 directly binds DNA in the absence of additional transcription factors

Having identified genes that were regulated by ABI4 in plants and yeast, yet lacked the consensus ABI4 binding 
Fig. 4 Synergistic activation of ABI4-regulated promoters by $\mathrm{ABI} 4$ and specific $\mathrm{ABI} 5 / \mathrm{ABF}$ bZIPs in yeast. Top, middle and bottom panels show activation by combination of ABI4 with ABI5, ABF1 or ABF3, respectively. Promoters that were strongly activated by any single bZIP factor were not tested for synergistic activation with ABI4. All data presented are the averages \pm standard deviation of assays on at least three samples, each representing many mating events site, we next analyzed ABI4 binding in vitro. We tested 6 of these ABI4-regulated promoters by electrophoretic mobility shift assays (EMSAs) with GST alone or fused to the ABI4 DNA binding domain, using promoter fragments between 150 and $350 \mathrm{bp}$ in length. A fragment of the ABI4 promoter previously characterized as containing ABI4 binding sites (Bossi et al. 2009) was included as a positive control. A GST fusion to the DNA-binding domain of $\mathrm{ABI} 4$, but not GST alone, bound the promoters of $4 \mathrm{ABI} 4$ targets tested although only one of these (At1g32560) contained the maize ABI4 binding site (Fig. 6a). The fragments that failed to bind were truncations of those used in the yeast one-hybrid assays and may have been missing
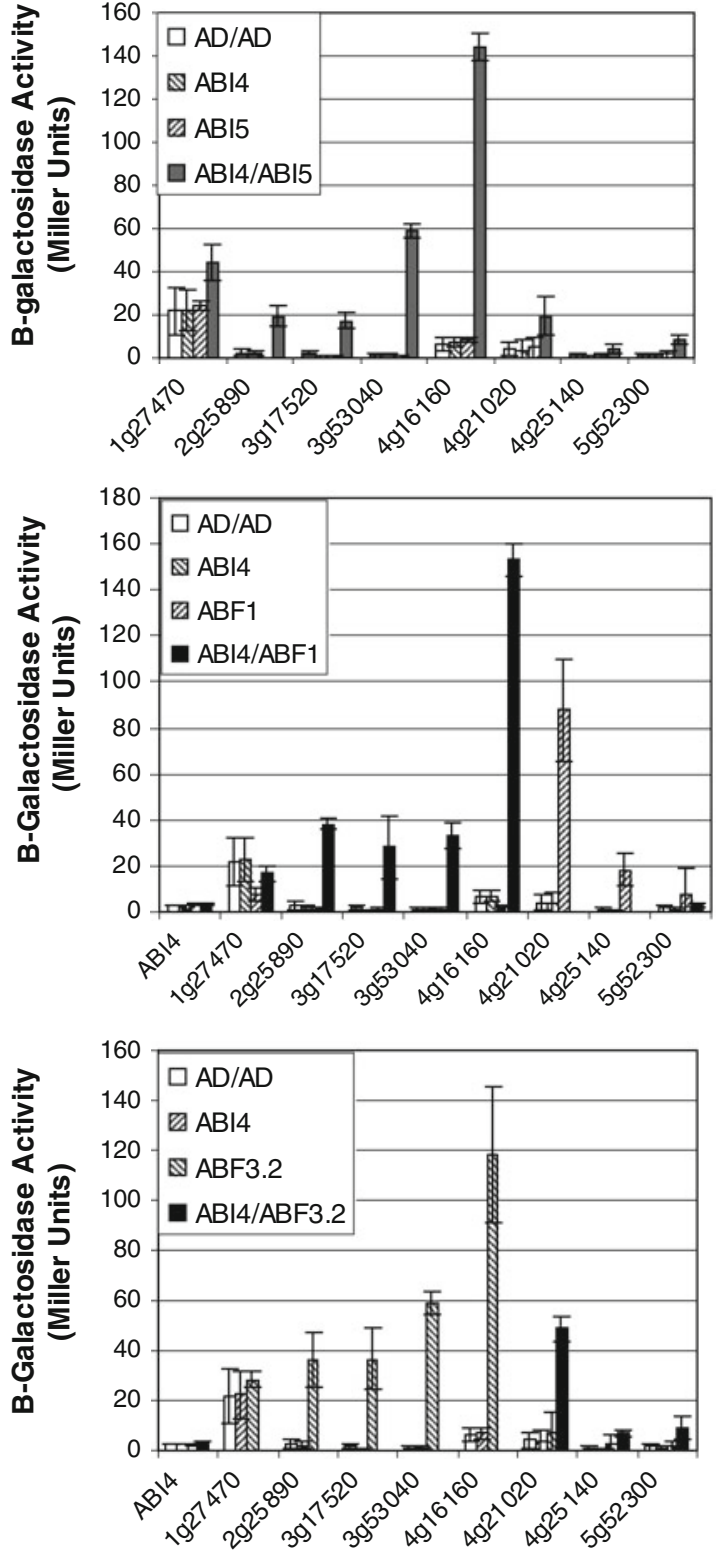

unidentified binding sites. Additional tests of smaller fragments of the At4g16160 promoter suggested that binding occurred within an approximately $50 \mathrm{bp}$ region containing a CCAC sequence that overlaps with one of the promoter's four ABREs (Supp. Fig. 6). However, the ABI4 target promoter fragments appeared to bind less specifically than the ABI4 upstream fragment, in that binding was disrupted nearly as well by non-specific competitor as by cold probe DNA (Fig. 6b). Although the ABI4 upstream fragment contains a CE1-like ABI4 binding site, it lacks any ABREs and was not activated by ABI4 alone or in combination with any bZIPs in the yeast one-hybrid assay (Fig. 4). 

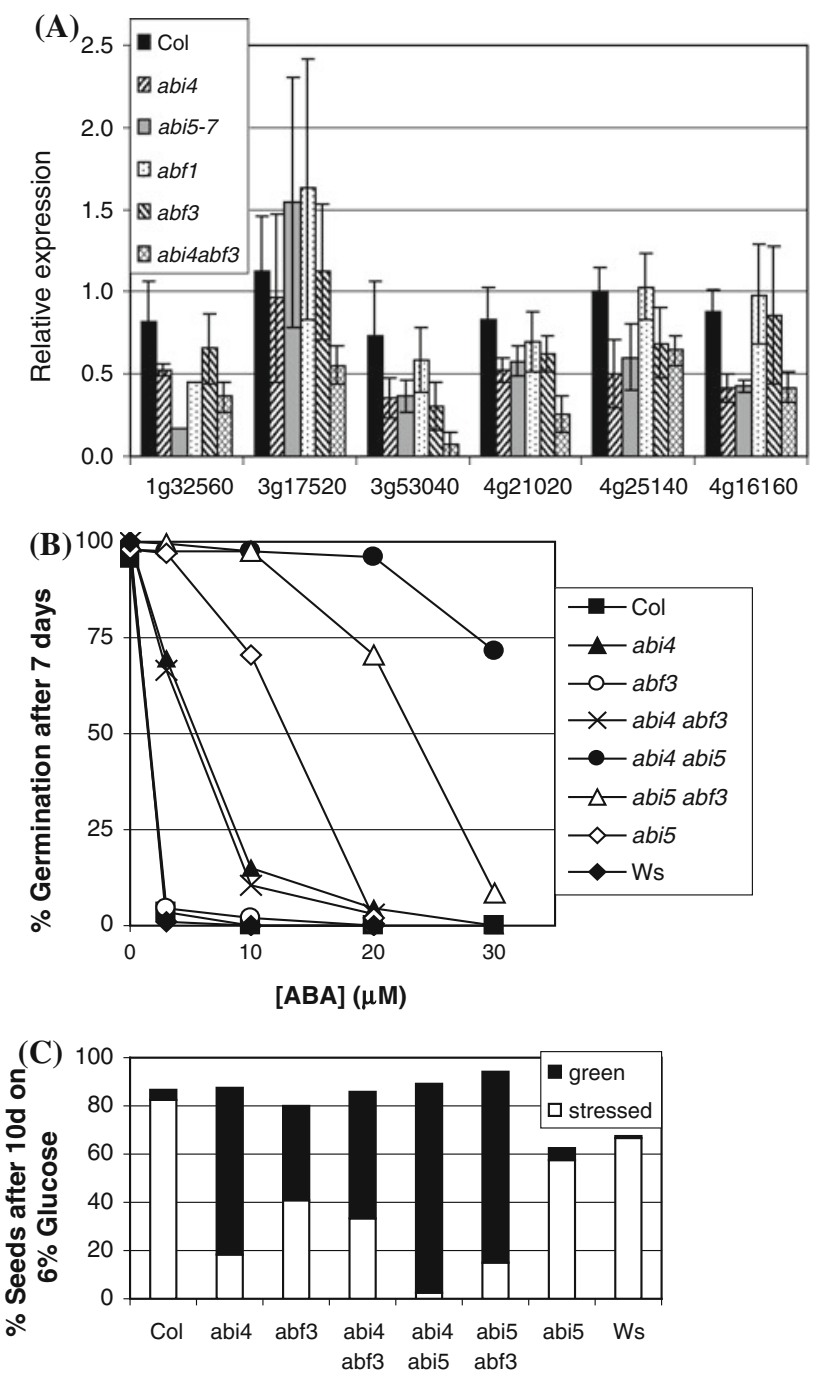

(D)

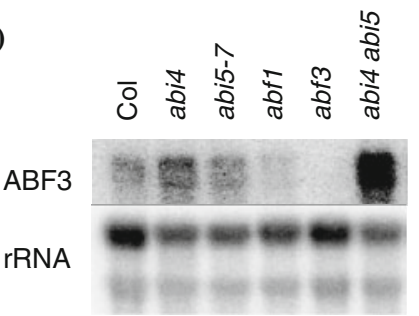

Fig. 5 Redundant function of $\mathrm{ABI} 4$ and $\mathrm{ABI} / \mathrm{ABF}$ bZIPs in seedlings. a Comparison of ABA/ABI-dependent gene expression in wild-type (Col) and mutant seedlings at 3 day post-stratification on GM supplemented with $5 \mu \mathrm{M}$ ABA. Expression levels shown are averages of duplicate assays of at least duplicate samples for each genotype, normalized relative to wild-type levels for each gene. b Comparison of ABA sensitivity in wild-type ( $\mathrm{Col}$ and Ws), mono and digenic mutant lines, based on radicle emergence after 7 day on minimal media supplemented with the indicated concentrations of ABA. c Comparison of glucose sensitivity, based on production of arrested pink or white (stressed) versus green seedlings after 10 day on minimal medium supplemented with $6 \%$ glucose. d ABF3 transcript accumulation in the indicated genotypes, assayed by RNA gel blot

\section{Discussion}

Summary of ABI-regulated gene classes

Confirming our initial hypotheses, the apparent targets of ectopic ABI4 and ABI5 expression showed some overlap during vegetative growth in overexpression lines. However, although only $12 \%$ appeared co-regulated in 11 day old overexpression lines, nearly $40 \%$ of these genes were regulated by both ABI4 and ABI5/related bZIP factors in seeds and seedlings. This discrepancy in overlap could reflect a block to expression in the older plants or indirect regulation in seeds such that more targets appear shared. Nearly $60 \%$ of the genes induced in 11 day old plants by both ABI factors encode proteins involved in seed maturation or stress response. Seed maturation genes are also over four times as prevalent among the set regulated by ABI4 alone compared to the ABI5-regulated set. Of the remaining ABI-regulated genes, the largest class encodes proteins of unknown function. Each ectopically expressed $\mathrm{ABI}$ factor also regulated distinct sets of genes involved in metabolism, cell structure and protein stability.

The last major category of ABI-regulated genes included additional transcription factors, protein kinases, and a protein phosphatase (AHG1) that was recently found to interact directly with an ABA receptor (Park et al. 2009), thereby confirming the hypothesis that ABI transcription factors regulate some signaling components generally assumed to act upstream in ABA signaling. Within this category, $\mathrm{ABI} 4$ induced the expression of three genes involved in the repression of ABA signaling: the protein phosphatase AHG1 (Nishimura et al. 2007) as well as the ABI5 interacting proteins AFP2 and AFP3 (Garcia et al. 2008). Although ABI4 is a positive regulator of ABA response, these results indicate that it may also play a key role in the feedback regulation of $\mathrm{ABA}$ signaling.

Advantages and limitations of ectopic expression for identifying ABI4 and ABI5 targets

A variety of microarray studies have analyzed the role of ABI transcription factors in gene regulation. These include the dry and imbibed seed comparisons for abi4 and abi5 mutants described above (Nakabayashi et al. 2005), comparison of endosperm versus embryo-expressed genes in germinating seeds (Penfield et al. 2006), ABI3-regulated genes in after-ripened or fresh (dormant) seeds (Carrera et al. 2008), targets of ectopically expressed maize VP1 (an $\mathrm{ABI} 3$ ortholog) in an abi3 mutant background (Suzuki et al. 2003), and targets of ectopically expressed ABI3 (Nakashima et al. 2006). Comparison of these lists shows sub- 
Fig. 6 ABI4 binds to promoter fragments lacking any characterized ABI4 binding site. Electrophoretic mobility shift assays (EMSAs) with promoter fragments from At1g32560 (310 bp), At1g27470 (329 bp), At4g16160 (295 bp),

At4g25140 (266 bp),

At2g25890 (301 bp),

At3g17520 (207 bp) or ABI4

(152 bp). The motifs contained within these fragments are indicated schematically.

a Comparison of binding by GST versus GST-ABI4 DNA binding domain fusion demonstrates interaction with the ABI4 domain.

b Competition with 50 - or 100-fold molar excess of nonradioactive probe $\left(5^{\prime} \mathrm{ABI} 4\right.$ or $\left.5^{\prime} 4 \mathrm{~g} 16160\right)$ or the $3^{\prime}$ UTR of $\mathrm{ABI} 4$

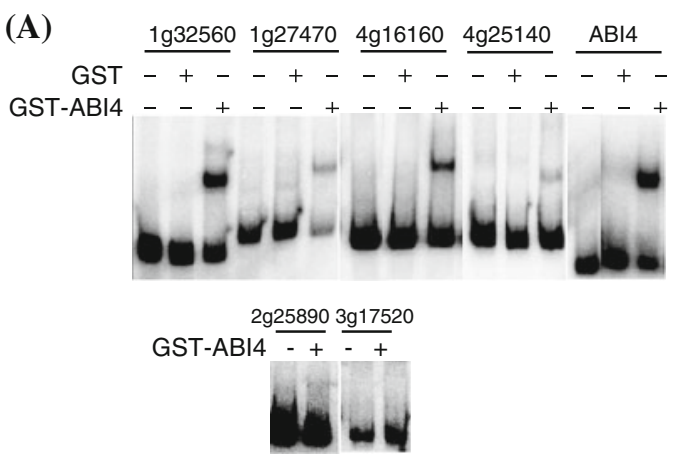

(B)

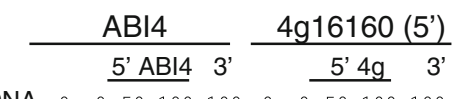

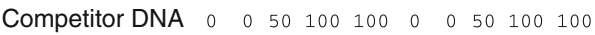
GST-ABI4 - + + + + - + + +

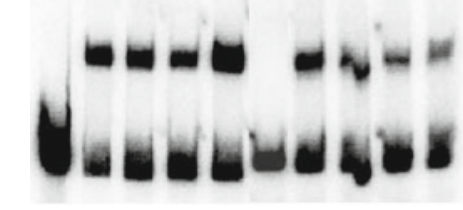

\% bound: $52 \quad 40 \quad 32 \quad 62 \quad 42 \quad 36 \quad 23 \quad 30$

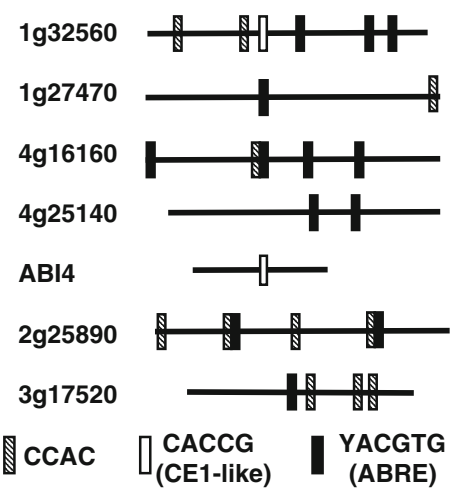

stantial overlap among the genes regulated by these $\mathrm{ABI}$ transcription factors. Although the VP1/ABI3 ectopic expression studies used distinct microarrays, each representing approximately $7 \mathrm{~K}$ genes, both showed that nearly $5 \%$ of the genes assayed were regulated by VP1/ABI3. Further comparisons, using the Expression Browser on BAR to analyze publicly available microarray data, showed that roughly $80 \%$ of the genes identified as regulated by $\mathrm{ABA}$ and VP1 or ABI3 in the ectopic expression studies were underexpressed in abi4 or abi5 mutants at $24 \mathrm{~h}$ after imbibition, when compared to fresh wild-type seeds. Similarly, over $60 \%$ of the ABI4 and/or ABI5 targets identified in the present study are underexpressed in abi3-4 mutants. A much smaller fraction appear underexpressed in all $a b i$ genotypes when compared to after-ripened wild-type seeds, presumably reflecting the higher commitment toward germination in all of these non-dormant seeds. The high degree of overlap among ABI-regulated genes probably reflects a combination of cross-regulation of these and other ABA response factors, and direct regulation of shared targets.

As discussed earlier, most of the genes induced by ectopic ABI expression are normally expressed in seeds, and many are regulated in seeds by the $A B I$ loci, supporting the validity of our approach. The relatively smaller fraction of genes that were not downregulated in $a b i$ seeds may be redundantly regulated by other transcription factors present in seeds. For example, some of these genes are also regulated by related bZIP factors during ABA-inhibited germination (Fig. 5). Our method therefore allowed us to identify genes that are directly regulated by, though not solely dependent on, ABI4 and ABI5.

In contrast to seed-expressed genes regulated by multiple $\mathrm{ABI}$ factors, the apparent 35S-ABI transcriptional targets that are not expressed in seeds might depend on interacting factors absent in dry or imbibing seeds. Although initially described as seed regulatory factors, ABI4 and ABI5 have subsequently been shown to function well into vegetative growth where they affect lateral root development (Signora et al. 2001), photosynthetically active gene expression (Acevedo-Hernandez et al. 2005), and pathogen response (Kaliff et al. 2007). It is possible that some of the ABI targets identified by our screen are involved in these vegetative responses.

Despite identifying these additional targets, the number of genes induced in our ectopic expression study is much lower than the number of genes whose expression is reduced in $a b i$ seeds (approximately three and tenfold lower for $A B I 4$ and $A B I 5$, respectively) (Nakabayashi et al. 2005); this could reflect indirect regulation in seeds, the strength of transgene expression, or a lack of interacting factors or chromatin accessibility required for expression in the older seedlings.

For example, promoter analyses suggest that our ABI5 regulated gene set is more enriched for direct ABI5 transcriptional targets than has been previously achieved using abi5 mutant lines. Only $40.3 \%$ of genes identified as ABI5 dependent in dry seeds contain the degenerate ABRE-like motif (Table 3) (Nakabayashi et al. 2005). Although this is 
a substantial enrichment over the genome-wide occurrence rate $(21 \%)$, it is much lower than the $71 \%$ of $35 \mathrm{~S}-\mathrm{ABI} 5$ induced genes that contained this motif. This suggests that many genes identified as ABI5 dependent in loss of function mutant studies are not direct targets of ABI5. Our list of ABI target genes, though significantly smaller than those identified in mutant studies, may offer a more accurate representation of the direct transcriptional targets of ABI4 and ABI5.

Nakabayashi et al. found that $14.6 \%$ of the genes underexpressed in abi5 mutant dry seeds were located near other downregulated genes, suggesting that their co-regulation was partly dependent on local chromosomal structure (Nakabayashi et al. 2005). Many seed specific genes are repressed during vegetative growth by chromatin remodeling that is dependent on PICKLE (Li et al. 2005), BRAHMA (Tang et al. 2008), Polycomb group proteins (Makarevich et al. 2006), trihelix repressors (Gao et al. 2009) and other factors. Previous studies have demonstrated that ectopic expression of B3 domain proteins such as the bean ABI3 homolog (PvALF) and, to a lesser extent, Arabidopsis FUS3 can modify chromatin structure to potentiate expression of seed genes in vegetative tissues upon subsequent induction by $\mathrm{ABA}$ ( $\mathrm{Li}$ et al. 1999; $\mathrm{Ng}$ and Hall 2008). In addition, ABI3 (or its monocot ortholog VP1) and ABI5 (or its rice homolog TRAB1) display direct and synergistic interactions in two-hybrid analyses in yeast and in transient reporter activation assays in rice protoplasts, consistent with a role for $\mathrm{ABI} 3$ in induction as well as potentiation (Finkelstein et al. 2005; Gampala et al. 2002; Nakamura et al. 2001). Although ectopic ABI5 expression is not sufficient to activate several seed-specific promoters, partly due to the limited activation potential of ABI5 (Bensmihen et al. 2004), co-expression with PvALF renders phaseolin induction $\mathrm{ABA}$-independent $(\mathrm{Ng}$ and Hall 2008). Our ectopic ABI5 expression lines lacked overexpressed $\mathrm{ABI} 3$ or similar seed transcription factors, and therefore may not have supported the vegetative induction of some genuine ABI5 targets. Consistent with this possibility, only two of the genes identified as induced by ABI5 overexpression in our microarrays $(3.3 \%)$ were associated with the abi5 downregulated gene clusters described in Nakabayashi et al. (2005).

Mechanism of ABI4 activation of genes lacking consensus ABI4 binding site

The ABI4-regulated genes identified in ectopic expression lines correlated strongly with ABI4-dependent expression in seeds. However, most lacked either the closely related S box or maize ABI4 binding sites. These ABI4 binding sites were originally identified on the basis of in vitro binding studies and comparisons of ABI4-regulated genes, and were functionally tested by reporter gene activation in protoplasts or yeast one-hybrid assays (Acevedo-Hernandez et al. 2005; Niu et al. 2002).

The documented ABI4 binding sites appear to have relatively low affinity and specificity of binding, since EMSAs require $\sim 100 \mathrm{ng}$ of fusion protein to shift $\sim 0.25 \mathrm{ng}$ DNA as compared to less than $25 \mathrm{ng}$ of purified protein for other transcription factor classes (Buratowski and Chodosh 2001). Furthermore, the documented sites include the motif in both the $5^{\prime}$ to $3^{\prime}$ and the $3^{\prime}$ to $5^{\prime}$ orientation, unusual for a non-palindromic recognition site (Acevedo-Hernandez et al. 2005). Our EMSAs demonstrated weakly selective binding to promoter fragments lacking the S-box [CACYKSCA] and related CE1-like binding site, indicating an even greater lack of specificity for DNA binding by ABI4.

Our functional assays were performed in yeast because this completely heterologous system lacks any additional plant factors that could contribute to promoter activation. For example, 35S-ABI4 expression in Arabidopsis results in ABA-inducible expression of $\mathrm{ABI} 3, \mathrm{ABI} 5$ and some related bZIPs (Brocard et al. 2002; Söderman et al. 2000). The presence of these additional factors in 11 day old plants or in transient assays in protoplasts could facilitate induction of ABI4 target genes that may require transcriptional activator synergy. In fact, all the target promoters we tested in yeast showed essentially no response to ABI4 alone, but several showed substantial synergy when ABI4 was combined with ABI5 or a related bZIP. The cooperative interaction of ABI4 and the bZIP transcription factors is also consistent with the significant enrichment of ABRE and ABRE-like motifs in the promoters of our 35S:ABI4 transcriptional target set. Furthermore, digenic mutant analyses showed that ABI4, ABI5 and ABF3 act redundantly in regulating some $\mathrm{ABA}$ responses in plants. Although we tested only $\mathrm{ABF} 1$ and $\mathrm{ABF} 3$ for synergy with $\mathrm{ABI} 4$, many of the ABI-regulated genes identified in our study were recently shown to be redundantly regulated by AREB1/ABF2, AREB2/ABF4, and ABF3 (Yoshida et al. 2010).

\section{Summary}

Our results identified a relatively small number of direct transcriptional targets for ABI4 and ABI5, many of which are a subset of genes previously shown to be underexpressed in abi4 and abi5 mutants. These targets included both positive and negative regulators of $\mathrm{ABA}$ response. Although there was some overlap of these targets and both gene sets were highly enriched for ABREs in their predicted promoter regions, the patterns of co-regulation for ABI4- and ABI5-regulated genes were quite different. 
Despite being tightly co-regulated in seeds, the promoters of the ABI4 target set were not significantly enriched for any previously described ABI4 binding sites, yet ABI4 was still able to bind some of these promoters in vitro. Finally, expression assays in a heterologous yeast system demonstrated that ABI4-regulated promoters could be synergistically induced by specific combinations of ABI4 and some bZIP factors, even when no canonical ABI4 binding sites were present, and that ABI4 binding alone was not sufficient for activation.

Acknowledgments We thank Terry Thomas and the Laboratory for Functional Genomics at TAMU for preliminary microarray data, the ABRC team at Ohio State University for efficient distribution of the T-DNA insertion lines from the SALK SIGnAL collection, and Luis Lopez-Molina for providing the abi5-7 seeds. This work was supported by National Science Foundation Grant IBN-0446048 to RRF. Funding for the SIGnAL indexed insertion mutant collection was provided by the National Science Foundation.

Open Access This article is distributed under the terms of the Creative Commons Attribution Noncommercial License which permits any noncommercial use, distribution, and reproduction in any medium, provided the original author(s) and source are credited.

\section{References}

Acevedo-Hernandez GJ, Leon P, Herrera-Estrella LR (2005) Sugar and $\mathrm{ABA}$ responsiveness of a minimal RBCS light-responsive unit is mediated by direct binding of ABI4. Plant J 43:506-519

Acharya BR, Assmann SM (2009) Hormone interactions in stomatal function. Plant Mol Biol 69:451-462

Alonso J, Stepanova A, Leisse T, Kim C, Chen H, Shinn P, Stevenson D, Zimmerman J, Barajas P, Cheuk R, Gadrinab C, Heller C, Jeske A, Koesema E, Meyers C, Parker H, Prednis L, Ansari Y, Choy N, Deen H, Geralt M, Hazari N, Hom E, Karnes M, Mulholland C, Ndubaku R, Schmidt I, Guzman P, AguilarHenonin L, Schmid M, Weigel D, Carter D, Marchand T, Risseeuw E, Brogden D, Zeko A, Crosby W, Berry C, Ecker J (2003) Genome-wide insertional mutagenesis of Arabidopsis thaliana. Science 301:549-716

Arenas-Huertero F, Arroyo A, Zhou L, Sheen J, Leon P (2000) Analysis of Arabidopsis glucose insensitive mutants, gin5 and gin6, reveals a central role of the plant hormone $\mathrm{ABA}$ in the regulation of plant vegetative development by sugar. Genes Dev 14:2085-2096

Bensmihen S, To A, Lambert G, Kroj T, Giraudat J, Parcy F (2004) Analysis of an activated ABI5 allele using a new selection method for transgenic Arabidopsis seeds. FEBS Lett 561: $127-131$

Bossi F, Cordoba E, Dupre P, Mendoza MS, Roman CS, Leon P (2009) The Arabidopsis ABA-INSENSITIVE (ABI) 4 factor acts as a central transcription activator of the expression of its own gene, and for the induction of $A B I 5$ and SBE2.2 genes during sugar signaling. Plant J 59:359-374

Brachmann CB, Davies A, Cost GJ, Caputo E, Li J, Hieter P, Boeke JD (1998) Designer deletion strains derived from Saccharomyces cerevisiae S288C: a useful set of strains and plasmids for PCRmediated gene disruption and other applications. Yeast 14: $115-132$
Brocard IM, Lynch TJ, Finkelstein RR (2002) Regulation and role of the Arabidopsis Abscisic acid-insensitive 5 gene in abscisic acid, sugar, and stress response. Plant Physiol 129:1533-1543

Buratowski S, Chodosh LA (2001) Mobility shift DNA-binding assay using gel electrophoresis. Curr Protoc Mol Biol Chapter 12, Unit 122

Carrera E, Holman T, Medhurst A, Dietrich D, Footitt S, Theodoulou FL, Holdsworth MJ (2008) Seed after-ripening is a discrete developmental pathway associated with specific gene networks in Arabidopsis. Plant J 53:214-224

Choi H, Hong J, Ha J, Kang J, Kim SY (2000) ABFs, a family of ABA-responsive element binding factors. J Biol Chem 275: $1723-1730$

Church GM, Gilbert W (1984) Genomic sequencing. Proc Natl Acad Sci U S A 81:1991-1995

Clough S, Bent A (1998) Floral dip: a simplified method for Agrobacterium-mediated transformation of Arabidopsis thaliana. Plant J 16:735-743

Cutler SR, Ehrhardt DW, Griffitts JS, Somerville CR (2000) Random GFP:cDNA fusions enable visualization of subcellular structures in cells of Arabidopsis at a high frequency. Proc Natl Acad Sci U S A 97:3718-3723

Cutler S, Rodriguez P, Finkelstein R, Abrams S (2010) Abscisic acid: emergence of a core signaling network. Annu Rev Plant Biol 61:651-679

Finkelstein RR (1994) Mutations at two new Arabidopsis ABA response loci are similar to the abi3 mutations. Plant J 5:765-771

Finkelstein RR, Gibson SI (2002) ABA and sugar interactions regulating development: cross-talk or voices in a crowd? Curr Opin Plant Biol 5:26-32

Finkelstein RR, Lynch TJ (2000) The Arabidopsis abscisic acid response gene $A B I 5$ encodes a basic leucine zipper transcription factor. Plant Cell 12:599-609

Finkelstein RR, Wang ML, Lynch TJ, Rao S, Goodman HM (1998) The Arabidopsis abscisic acid response locus ABI4 encodes an APETALA 2 domain protein. Plant Cell 10:1043-1054

Finkelstein RR, Gampala SS, Rock CD (2002) Abscisic acid signaling in seeds and seedlings. Plant Cell 14(Suppl):S15-45

Finkelstein R, Gampala SS, Lynch TJ, Thomas TL, Rock CD (2005) Redundant and distinct functions of the ABA response loci $A B A-$ INSENSITIVE(ABI)5 and ABRE-BINDING FACTOR (ABF)3. Plant Mol Biol 59:253-267

Gampala SS, Finkelstein RR, Sun SS, Rock CD (2002) ABI5 interacts with abscisic acid signaling effectors in rice protoplasts. J Biol Chem 277:1689-1694

Gao MJ, Lydiate DJ, Li X, Lui H, Gjetvaj B, Hegedus DD, Rozwadowski K (2009) Repression of seed maturation genes by a trihelix transcriptional repressor in Arabidopsis seedlings. Plant Cell 21:54-71

Garcia ME, Lynch T, Peeters J, Snowden C, Finkelstein R (2008) A small plant-specific protein family of $\mathrm{ABI}$ five binding proteins (AFPs) regulates stress response in germinating Arabidopsis seeds and seedlings. Plant Mol Biol 67:643-658

Giraud E, Van Aken O, Ho LH, Whelan J (2009) The transcription factor ABI4 is a regulator of mitochondrial retrograde expression of ALTERNATIVE OXIDASE1a. Plant Physiol 150:1286-1296

Giraudat J, Hauge BM, Valon C, Smalle J, Parcy F, Goodman HM (1992) Isolation of the Arabidopsis $A B I 3$ gene by positional cloning. Plant Cell 4:1251-1261

Goda H, Sasaki E, Akiyama K, Maruyama-Nakashita A, Nakabayashi K, Li W, Ogawa M, Yamauchi Y, Preston J, Aoki K, Kiba T, Takatsuto S, Fujioka S, Asami T, Nakano T, Kato H, Mizuno T, Sakakibara H, Yamaguchi S, Nambara E, Kamiya Y, Takahashi H, Hirai MY, Sakurai T, Shinozaki K, Saito K, Yoshida S, Shimada Y (2008) The AtGenExpress hormone and chemical 
treatment data set: experimental design, data evaluation, model data analysis and data access. Plant J 55:526-542

Guarente L, Mason T (1983) Heme regulates transcription of the CYC1 gene of $S$. cerevisiae via an upstream activation site. Cell 32:1279-1286

Hruz T, Laule O, Szabo G, Wessendorp F, Bleuler S, Oertle L, Widmayer P, Gruissem W, Zimmermann P (2008) Genevestigator v3: a reference expression database for the meta-analysis of transcriptomes. Adv Bioinform 2008:420747

Hughes JD, Estep PW, Tavazoie S, Church GM (2000) Computational identification of Cis-regulatory elements associated with groups of functionally related genes in Saccharomyces cerevisiae. J Mol Biol 296:1205-1214

Kaliff M, Staal J, Myrenas M, Dixelius C (2007) ABA is required for Leptosphaeria maculans resistance via ABI1- and ABI4-dependent signaling. Mol Plant Microbe Interact 20:335-345

Kilian J, Whitehead D, Horak J, Wanke D, Weinl S, Batistic O, D'Angelo C, Bornberg-Bauer E, Kudla J, Harter K (2007) The AtGenExpress global stress expression data set: protocols, evaluation and model data analysis of UV-B light, drought and cold stress responses. Plant J 50:347-363

Kim SY, Ma J, Perret P, Li Z, Thomas TL (2002) Arabidopsis ABI5 subfamily members have distinct DNA-binding and transcriptional activities. Plant Physiol 130:688-697

Koussevitzky S, Nott A, Mockler TC, Hong F, Sachetto-Martins G, Surpin M, Lim J, Mittler R, Chory J (2007) Signals from chloroplasts converge to regulate nuclear gene expression. Science 316:715-719

Laby RJ, Kincaid MS, Kim D, Gibson SI (2000) The Arabidopsis sugar-insensitive mutants sis4 and sis5 are defective in abscisic acid synthesis and response. Plant J 23:587-596

Li G, Bishop KJ, Chandrasekharan MB, Hall TC (1999) betaPhaseolin gene activation is a two-step process: PvALF- facilitated chromatin modification followed by abscisic acid-mediated gene activation. Proc Natl Acad Sci U S A 96:7104-7109

Li HC, Chuang K, Henderson JT, Rider SD Jr, Bai Y, Zhang H, Fountain M, Gerber J, Ogas J (2005) PICKLE acts during germination to repress expression of embryonic traits. Plant $\mathrm{J}$ 44:1010-1022

Liu Q, Li MZ, Leibham D, Cortez D, Elledge SJ (1998) The univector plasmid-fusion system, a method for rapid construction of recombinant DNA without restriction enzymes. Curr Biol 8:1300-1309

Liu X, Brutlag D, Liu J (2001) BioProspector: discovering conserved DNA motifs in upstream regulatory regions of co-expressed genes. Pac Symp Biocomput 127-138

Lopez-Molina L, Chua NH (2000) A null mutation in a bZIP factor confers ABA-insensitivity in Arabidopsis thaliana. Plant Cell Physiol 41:541-547

Lopez-Molina L, Mongrand S, Chua NH (2001) A postgermination developmental arrest checkpoint is mediated by abscisic acid and requires the ABI5 transcription factor in Arabidopsis. Proc Natl Acad Sci U S A 98:4782-4787

Lopez-Molina L, Mongrand S, McLachlin DT, Chait BT, Chua NH (2002) ABI5 acts downstream of ABI3 to execute an ABAdependent growth arrest during germination. Plant J 32:317-328

Makarevich G, Leroy O, Akinci U, Schubert D, Clarenz O, Goodrich J, Grossniklaus U, Kohler C (2006) Different Polycomb group complexes regulate common target genes in Arabidopsis. EMBO Rep 7:947-952

Nakabayashi K, Okamoto M, Koshiba T, Kamiya Y, Nambara E (2005) Genome-wide profiling of stored mRNA in Arabidopsis thaliana seed germination: epigenetic and genetic regulation of transcription in seed. Plant J 41:697-709

Nakamura S, Lynch TJ, Finkelstein RR (2001) Physical interactions between ABA response loci of Arabidopsis. Plant J 26:627-635
Nakashima K, Fujita Y, Katsura K, Maruyama K, Narusaka Y, Seki M, Shinozaki K, Yamaguchi-Shinozaki K (2006) Transcriptional regulation of ABI3- and ABA-responsive genes including $\mathrm{RD} 29 \mathrm{~B}$ and RD29A in seeds, germinating embryos, and seedlings of Arabidopsis. Plant Mol Biol 60:51-68

Nambara E, Suzuki M, Abrams S, McCarty DR, Kamiya Y, McCourt $P$ (2002) A screen for genes that function in abscisic acid signaling in Arabidopsis thaliana. Genetics 161:1247-1255

Ng DWK, Hall TC (2008) PvALF and FUS3 activate expression from the phaseolin promoter by different mechanisms. Plant Mol Biol 66:233-244

Nishimura N, Yoshida T, Kitahata N, Asami T, Shinozaki K, Hirayama T (2007) ABA-Hypersensitive Germination1 encodes a protein phosphatase $2 \mathrm{C}$, an essential component of abscisic acid signaling in Arabidopsis seed. Plant J 50:935-949

Niu X, Helentjaris T, Bate NJ (2002) Maize ABI4 binds coupling element 1 in abscisic acid and sugar response genes. Plant Cell 14:2565-2575

Obrdlik P, El-Bakkoury M, Hamacher T, Cappellaro C, Vilarino C, Fleischer C, Ellerbrok H, Kamuzinzi R, Ledent V, Blaudez D, Sanders D, Revuelta JL, Boles E, Andre B, Frommer WB (2004) $\mathrm{K}+$ channel interactions detected by a genetic system optimized for systematic studies of membrane protein interactions. Proc Natl Acad Sci U S A 101:12242-12247

Ohme-Takagi M, Shinshi H (1995) Ethylene-inducible DNA binding proteins that interact with an ethylene-responsive element. Plant Cell 7:173-182

Parcy F, Valon C, Raynal M, Gaubier-Comella P, Delseny M, Giraudat J (1994) Regulation of gene expression programs during Arabidopsis seed development: roles of the $A B I 3$ locus and of endogenous abscisic acid. Plant Cell 6:1567-1582

Park SY, Fung P, Nishimura N, Jensen DR, Fujii H, Zhao Y, Lumba S, Santiago J, Rodrigues A, Chow TF, Alfred SE, Bonetta D, Finkelstein R, Provart NJ, Desveaux D, Rodriguez PL, McCourt P, Zhu JK, Schroeder JI, Volkman BF, Cutler SR (2009) Abscisic acid inhibits type 2C protein phosphatases via the PYR/ PYL family of START proteins. Science 324:1068-1071

Pavesi G, Mereghetti P, Mauri G, Pesole G (2004) Weeder Web: discovery of transcription factor binding sites in a set of sequences from co-regulated genes. Nucleic Acids Res 32:W199-W203

Penfield S, Li Y, Gilday AD, Graham S, Graham IA (2006) Arabidopsis ABA INSENSITIVE4 regulates lipid mobilization in the embryo and reveals repression of seed germination by the endosperm. Plant Cell 18:1887-1899

Quesada V, Ponce MR, Micol JL (2000) Genetic analysis of salttolerant mutants in Arabidopsis thaliana. Genetics 154:421-436

Rook F, Corke F, Card R, Munz G, Smith C, Bevan MW (2001) Impaired sucrose-induction mutants reveal the modulation of sugar-induced starch biosynthetic gene expression by abscisic acid signalling. Plant J 26:421-433

Sakuma Y, Liu Q, Dubouzet JG, Abe H, Shinozaki K, YamaguchiShinozaki K (2002) DNA-binding specificity of the ERF/AP2 domain of Arabidopsis DREBs, transcription factors involved in dehydration- and cold-inducible gene expression. Biochem Biophys Res Comm 290:998-1009

Shinozaki K, Yamaguchi-Shinozaki K (2007) Gene networks involved in drought stress response and tolerance. J Exp Bot $58: 221-227$

Signora L, De Smet I, Foyer CH, Zhang H (2001) ABA plays a central role in mediating the regulatory effects of nitrate on root branching in Arabidopsis. Plant J 28:655-662

Söderman EM, Brocard IM, Lynch TJ, Finkelstein RR (2000) Regulation and function of the Arabidopsis ABA-insensitive4 gene in seed and abscisic acid response signaling networks. Plant Physiol 124:1752-1765 
Suzuki M, Ketterling MG, Li QB, McCarty DR (2003) Viviparous1 alters global gene expression patterns through regulation of abscisic acid signaling. Plant Physiol 132:1664-1677

Tang X, Hou A, Babu M, Nguyen V, Hurtado L, Lu Q, Reyes JC, Wang A, Keller WA, Harada JJ, Tsang EW, Cui Y (2008) The Arabidopsis BRAHMA chromatin-remodeling ATPase is involved in repression of seed maturation genes in leaves. Plant Physiol 147:1143-1157

Thijs G, Marchal K, Lescot M, Rombauts S, De Moor B, Rouzé P, Moreau Y (2002) A gibbs sampling method to detect overrepresented motifs in the upstream regions of coexpressed genes. J Comput Biol 9:447-464

Toufighi K, Brady SM, Austin R, Ly E, Provart NJ (2005) The botany array resource: e-Northerns, expression angling, and promoter analyses. Plant J 43:153-163
Uno Y, Furihata T, Abe H, Yoshida R, Shinozaki K, YamaguchiShinozaki K (2000) Arabidopsis basic leucine zipper transcription factors involved in an abscisic acid-dependent signal transduction pathway under drought and high-salinity conditions. Proc Natl Acad Sci USA 97:11632-11637

Yoshida T, Fujita Y, Sayama H, Kidokoro S, Maruyama K, Mizoi J, Shinozaki K, Yamaguchi-Shinozaki K (2010) AREB1, AREB2, and $\mathrm{ABF} 3$ are master transcription factors that cooperatively regulate ABRE-dependent $\mathrm{ABA}$ signaling involved in drought stress tolerance and require $\mathrm{ABA}$ for full activation. Plant $\mathrm{J}$ 61:672-685 